\title{
AS DIFICULDADES NA IMPLANTAÇÃO DE PRÁTICAS SUSTENTÁVEIS NA GESTÃO PÚBLICA: ESTUDO DE CASO DE UNIVERSIDADE PÚBLICA BRASILEIRA - USO RACIONAL DE PAPEL VERSUS GESTÃO ELETRÔNICA
}

THE DIFFICULTIES IN THE IMPLANTATION OF SUSTAINABLE PRACTICES IN PUBLIC MANAGEMENT: CASE STUDY OF BRAZILIAN PUBLIC UNIVERSITY RATIONAL USE OF PAPER VERSUS ELECTRONIC MANAGEMENT

\author{
Delaine Goulart Rocha \\ Universidade de São Paulo, São Paulo, SP, Brasil. \\ E-mail:delaine@usp.br \\ Luciano Mitidieri Bento Garcia \\ Universidade de São Carlos, São Carlos, SP, Brasil. \\ E-mail: lucianogarcia@ufscar.br \\ Vanessa da Silva Mariotto Onody \\ Universidade de São Carlos, São Carlos, SP, Brasil. \\ E-mail:vamariotto@ufscar.br
}

Recebido em: 08.09.2017 - Aceito em: 27.01.2018

DOI: http://dx.doi.org/10.5902/2526629228972

\section{RESUMO}

Este artigo, teórico-empírico de natureza qualitativa, é o resultado da análise de um estudo para implementação de práticas sustentáveis na condução dos processos públicos em uma universidade pública brasileira. Objetivou-se analisar as dificuldades para implantação e continuidade da redução do uso de papel no setor público. Como método, foi realizada a coleta de dados, por meio de entrevistas, com os participantes e não participantes de um programa de práticas sustentáveis estimulado pela instituição. A análise deste estudo fundamentou-se na comunicação dialógica sob a ótica do filósofo Mikhail Bakhtin. Os dados analisados na visão qualitativa permitem concluir que o modelo organizacional afeta diretamente a manutenção de práticas. O resultado contribuiu para contextualizar os desafios da execução de práticas sustentáveis no setor público, e o trabalho serve de referência para outras universidades públicas brasileiras interessadas em adotar práticas sustentáveis em sua gestão.

PALAVRAS-CHAVE: Práticas sustentáveis; Gestão pública; Gestão ambiental.

\section{ABSTRACT}


This article, theoretical-empirical of qualitative nature, is the result of the analysis of a study for the implementation of sustainable practices in the conduction of Public Processes in Brazilians Publics Universities. The objective was to analyze the difficulties for implementation and continuity of the reduction of the use of paper in the public sector. As a method, data were collected through interviews with participants and non-participants of a program of sustainable practices stimulated by the institution. The analysis of this study was based on the dialogical communication from the perspective of the philosopher Mikhail Bakhtin. The data analyzed in the qualitative view allow to conclude that the organizational model directly affects the maintenance of practices. The result contributed to contextualize the challenges of implementing sustainable practices in the public sector; and the work serves as a reference for other Brazilian public universities interested in adopting sustainable practices in their management.

KEYWORDS: Sustainable practices; Public management; Environmental.

\section{INTRODUÇÃO}

Durante as últimas décadas, agravou-se o problema ambiental na Terra em decorrência da intensa industrialização e do consequente aumento da intervenção do homem na natureza. Isso gerou um processo de degradação com consequências trágicas para a vida humana. Esse cenário mobilizou os governantes de muitos países do mundo em conferências mundiais, na busca por uma solução para um desenvolvimento consciente, diminuindo o impacto ambiental (Dias, 2011).

Os encontros entre cientistas e líderes de países, como o Relatório Brundtland (1987) e o Rio 92, confirmaram a necessidade de aplicação de programas de desenvolvimento fundamentados em questões ambientais, de sustentabilidade e de conscientização. O conceito de sustentabilidade enfoca a equidade social e a qualidade de vida desta e das próximas gerações (Costa, Damasceno, \& Santos, 2012).

O relatório da Comissão de Brundtland, intitulado "Nosso Futuro Comum", destacou a responsabilidade e o impacto das atividades industriais no desenvolvimento sustentável e ofereceu uma visão de crescimento econômico sustentável e da elevada qualidade ambiental que pode ser alcançada através de boas práticas industriais, como, por exemplo, produzir mais com menos (Dias, 2011).

Nesse âmbito empresarial, as três dimensões da sustentabilidade se identificam como conceito de Triple Bottom Line, ou seja, o tripé da sustentabilidade que reflete um conjunto de valores, objetivos e processos que uma organização deve 
focar para criar valor: econômico, social e ambiental (Dias, 2011) (ver Figura 1).

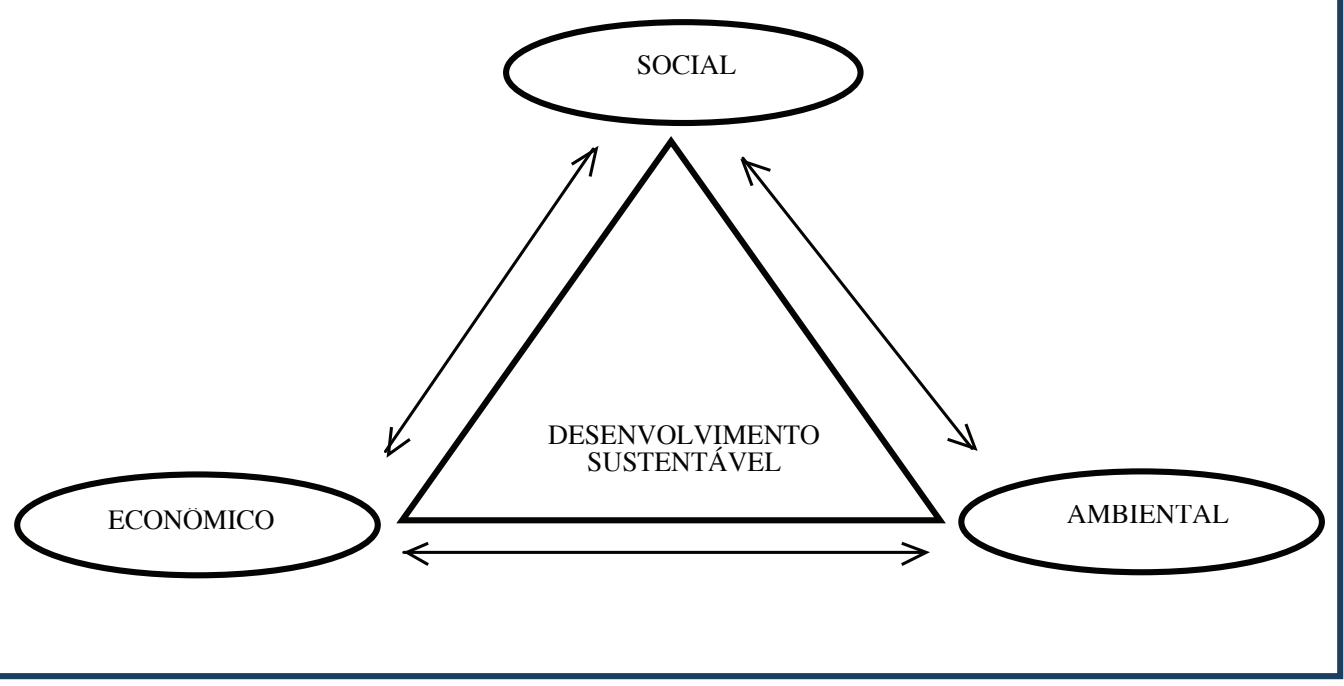

Figura 1 - Equilíbrio dinâmico da sustentabilidade

Fonte: Dias (2011, p. 46).

Observa-se que o conceito não é tão simples se aplicado em uma sociedade constituída por um ambiente formado por indivíduos que são dotados de interesses e recursos de poder diferenciados e que interagem continuamente a fim de satisfazer as suas necessidades (Rua, 2012).

Uma análise dos processos de trabalho no serviço público, detalhados por Bergue (2010), revela que nesse ambiente as rotinas são relativamente estáveis, ou seja, elas acontecem conforme uma sucessão de atividades que consomem recursos e geram um resultado pretendido, ambos marcados por um sensível grau de perenidade, resistente a mudanças.

Nos conceitos apresentados, é preciso estabelecer um parâmetro para que os impactos requeridos pela implementação da sustentabilidade sejam mínimos nos processos de trabalho do serviço público. Tem-se um ambiente constituído por uma sociedade que é caracterizada por sua diferenciação e que inclui as instituições públicas (Dias, 2011).

Em um ambiente como esse, parâmetros são necessários a fim de minimizar os impactos previstos na implantação da sustentabilidade Triple Bottom Line nos processos de trabalho do serviço público (Dias, 2011).

Sorrentino, Trajber, Mendonça, e Ferrraro Junior (2005), por exemplo, ao se aprofundarem sobre a Educação Ambiental como política pública, salientam a importância de um processo dialético de transformação social e cultural e enfatizam 
a necessidade de uma nova ordem de valores para absorção de uma educação ambiental apurada e, possivelmente, adaptada aos processos públicos.

Mesmo diante de resistências, percebe-se que a sustentabilidade de ações e a necessidade de programas desenvolvidos pela Administração Pública para promover o uso racional dos recursos passou a ser uma das principais preocupações dos cidadãos (Couto \& Coelho, 2015).

Diante de uma necessidade latente, este estudo visa identificar as dificuldades para implantação de práticas sustentáveis na gestão dos processos públicos. Trata-se de um estudo de caso em universidade pública brasileira sobre uso racional do papel versus gestão eletrônica.

O método utilizado foi o indutivo, por meio de questionário, estabelecido em premissas baseadas na observação dos fenômenos, na descoberta e na relação entre eles (Lakatos \& Markoni, 2003).

Estudos do filósofo Mikhail Bakhtin inferem que a linguagem, seja ela escrita ou falada, é resultado de um produto social de vivências. Bakhtin detalha que a linguagem é como um produto social dotado de convenções necessárias, referenciadas pelo corpo social, que possibilitam o exercício da comunicação (Faraco, 2009).

A organização, ao conhecer a linguagem, conforme detalhado por Bakhtin (1979), pode decifrá-la e atingir o seu objetivo, com a aplicação de uma gestão voltada para o alcance de um público que represente o universo. Neste estudo, relacionam-se os conceitos apresentados entendendo a instituição como um organismo dotado de administração de atividades e como um universo social (Faraco, 2009).

Este artigo é resultado do trabalho alicerçado sobre o ponto de vista administrativo e sociológico e irá indicar que as ações sustentáveis em ambientes públicos são incipientes por causa da burocratização de algumas atividades carregadas de legalismo, ou seja, práticas condicionadas pela cultura e patrimonialismo das instituições públicas.

\section{REFERENCIAL TEÓRICO}

\section{1 aspecto legal da evolução eletrônica}

No Brasil, principalmente a partir de 1960, com o aumento da industrialização, a intensa urbanização e o crescimento demográfico provocaram impactos no meio ambiente que podem ser percebidos com intensidade nos últimos anos. Devido a isso, nos anos seguintes, o governo brasileiro viabilizou a criação de ór- 
gãos ambientais instruídos para atuar como eixos centrais de controle de agentes degradantes, como a poluição (Dias, 2011).

A Lei $n^{\circ}$ 9.795/1999, por exemplo, que dispõe sobre a Política Nacional de Educação Ambiental, em seu artigo $1^{\circ}$, registra que:

Entende-se por educação ambiental os processos por meio dos quais o indivíduo e a coletividade constroem valores sociais, conhecimentos, habilidades, atitudes e competências voltadas para a conservação do meio ambiente, bem de uso comum do povo, essencial à sadia qualidade de vida e sua sustentabilidade. (Brasil, 2016).

Além do âmbito educacional contemplado na lei citada, a questão ambiental é constantemente assunto dos meios de comunicação que informam a incidência de fatos relevantes que afetam diretamente a vida das pessoas (poluição, catástrofes, entre outros). Isso gera a necessidade de criação e atualização da legislação vigente.

A Lei $n^{\circ}$ 8.666, de 21 de julho de 1993, que institui normas sobre as licitações e contratos da Administração Pública, foi revisada em 2010, com a menção expressa de que o desenvolvimento nacional sustentável é um dos objetivos a serem almejados pelos certames licitatórios em todos os níveis da Administração Pública no Brasil (Brasil, 2016).

Nesse sentido há algumas regras que dispõem sobre critérios de sustentabilidade ambiental a serem seguidas na contratação de obras e serviços e na aquisição de bens pela Administração Pública Federal.

Nessa perspectiva, o Tribunal de Contas da União determina que os processos sustentáveis que extinguem a cultura poluidora na Administração reduzam os custos do governo e tragam benefícios para o conjunto da sociedade (Vogelmann, 2014).

Em relação à documentação digital, percebe-se que as regulamentações que regem o serviço público já permitem que todo ato administrativo seja gerado e confirmado em meio eletrônico (Medida Provisória $n^{\circ}$ 2.200/2001 e Lei Federal $\left.n^{\circ} 12.682 / 2012\right)$.

Sobre a gestão eletrônica de documentos públicos, está disponível um manual técnico, intitulado e-ARQ Brasil: modelo de requisitos para sistemas informatizados de gestão arquivística de documentos, que detalha elementos importantes sobre a arquivística de documentos, elaborado pela Câmara Técnica de Documentos Eletrônicos (CTDE) do Conselho Nacional de Arquivos (Conarq).

Importante mencionar que, a partir do ano 2000, o Governo Brasileiro, por iniciativa do Ministério do Planejamento, lançou a Proposta de Política de Gover- 
no Eletrônico, que disponibilizou 629 serviços e 3.500 informações em um portal federal a fim de conferir-Ihes transparência pública (Santos \& Cruz, 2017).

Percebe-se que a visão do cidadão em relação ao governo assume uma característica promissora que eleva o servidor público à categoria de agente proativo e compromissado com a inclusão digital (Santos \& Cruz, 2017).

É evidente que a velocidade da informação digital avançou sobre a constituição legal, estabelecendo entre eles um distanciamento. A necessidade de legitimidade dos documentos públicos ocasiona entraves na redução de papel e implantação da gestão eletrônica de documentos. Na instituição estudada, o órgão responsável pelo assunto em questão ainda discute o programa de gestão eletrônica e não apresenta consenso sobre a redução de papel e a aplicação de gestão eletrônica para a condução da grande maioria de seus processos.

Como apresentado, houve um avanço da legislação para respaldo em práticas sustentáveis em diversos segmentos, porém o assunto ainda é pouco discutido nas instituições públicas de ensino. Percebe-se um efeito descoordenado entre a legislação e sua aplicação no serviço público.

\subsection{Práticas sustentáveis}

O conceito de desenvolvimento sustentável nas organizações exige uma gestão mais eficiente, com práticas identificadas com a ecoeficiência, por se tratar de tendência para o desenvolvimento econômico, porém as organizações estão longe de se tornar agentes de um desenvolvimento sustentável, socialmente justo e ambientalmente correto (Dias, 2011).

Dias (2011) ressalta que, para atingir um desenvolvimento de práticas sustentáveis na organização, é necessária a implantação de uma cultura ambiental que envolva todos os níveis na organização, na projeção e implementação de tarefas.

A existência das organizações está relacionada à distribuição e à execução de tarefas, e isso se dá por intermédio das pessoas, que, por sua vez, não se dissociam de suas escalas sociais de valores éticos. Assim, a cultura da organização pode ser sinteticamente definida como um conjunto de hábitos, crenças, valores e símbolos que a particularizam frente às demais (Bergue, 2010).

Ao detalhar a organização pública, Bergue (2010) salienta que a estrutura de valores é bastante complexa e carregada de fatores históricos que influenciam e regulamentam seu processo de transformação. O patrimonialismo e a burocracia, por exemplo, são valores que interferem na condução de processos e tendem 
a uma resistência de movimentos que geram uma acomodação em relação aos padrões culturais tradicionais.

Diante do exposto, Vogelmann (2014) explica que uma postura sustentável não é tão simples. A sustentabilidade, em sua concepção geral, traz desafios aos gestores nos campos social, econômico e ambiental e demanda uma profunda educação de todos os atores envolvidos nos processos relacionados com as mencionadas temáticas.

Os hábitos antigos relacionados com parâmetros de consumo poluidores não desaparecem da noite para o dia, o que demanda esforço para substituir ações impensadas por ações sustentáveis.

Ao comentar sobre a resistência à mudança, Bergue (2010) ressalta que a resistência pode ser minimizada, ou mesmo elidida, se o indivíduo ou grupo destinatário da mudança for capaz de constatar resultado positivo no balanço de perdas e ganhos decorrentes da inovação, ou seja, a resistência à mudança deve ser compreendida como um sistema de resultados que avalia o quanto haverá de perda pessoal em relação ao ganho conquistado.

A fim de ilustrar a resistência a mudanças, alguns dos pressupostos e contrapressupostos devem ser descritos (Hernandes \& Caldas, 2011), conforme apresentado na Tabela 1, a seguir.

Tabela 1 - Resistência à mudança

\begin{tabular}{l|l}
\hline \multicolumn{1}{c|}{ Pressupostos } & \multicolumn{1}{c}{ Contrapressupostos } \\
\hline $\begin{array}{l}\text { A resistência à mudança é um fato da } \\
\text { vida e deve acontecer durante qualquer } \\
\text { intervenção organizacional. }\end{array}$ & $\begin{array}{l}\text { A resistência é um comportamento alardeado } \\
\text { pelos detentores de poder e pelos agentes de } \\
\text { mudança quando são desafiados em seus pri- } \\
\text { vilégios ou ações. }\end{array}$ \\
\hline $\begin{array}{l}\text { A resistência à mudança é maléfica aos } \\
\text { esforços de mudança organizacional. }\end{array}$ & $\begin{array}{l}\text { A resistência é um fenômeno saudável e contri- } \\
\text { butivo, porém usada como uma desculpa para } \\
\text { processos de mudança fracassados. }\end{array}$ \\
\hline $\begin{array}{l}\text { Os seres humanos são naturalmente re- } \\
\text { sistentes à mudança - resistem à perda. }\end{array}$ & $\begin{array}{l}\text { Os seres humanos desejam a mudança: tal } \\
\text { necessidade tipicamente se sobrepõe ao medo } \\
\text { do desconhecido. }\end{array}$ \\
\hline $\begin{array}{l}\text { Os empregados são os atores organiza- } \\
\text { cionais com maior probabilidade de re- }\end{array}$ & $\begin{array}{l}\text { A resistência, quando ocorre, pode acontecer } \\
\text { entre os gestores, agentes de mudança e em- } \\
\text { sistir à mudança. }\end{array}$ \\
\hline $\begin{array}{l}\text { A resistência à mudança é um fenômeno } \\
\text { grupal/coletivo. }\end{array}$ & $\begin{array}{l}\text { A resistência é tanto individual quanto coletiva, } \\
\text { varia de uma pessoa para outra, em função de } \\
\text { muitos fatores situacionais e perceptivos. }\end{array}$ \\
\hline
\end{tabular}

Fonte: adaptado de Hernandes e Caldas (2011, p. 37).

Sobre a redução do papel, Vogelmann (2014) ressalta ser (o papel) um dos 
insumos mais utilizados pelos órgãos públicos em geral, devido à prática de documentar e formalizar todos os atos governamentais. O insumo, aparentemente inofensivo, ataca a natureza em dois pontos: a retirada de grandes volumes de madeira e a utilização de grande quantidade de energia para sua fabricação. Economizar papel, portanto, é preservar a natureza.

Vogelmann (2014) apresenta uma lista de ações de fácil execução que podem ser implementadas em nível operacional; porém, no estudo de caso analisado, percebem-se variações importantes em propostas de práticas simples, como, por exemplo, impressões frente e verso e/ou uso de rascunhos para impressões internas.

\subsection{As práticas sustentáveis e o educador ambiental}

Conforme Dias (2011) enfatiza, ações sustentáveis necessitam de conscientização, já que a atividade que busca a preservação do meio ambiente inicia-se e concretiza-se alterando o comportamento das pessoas que interagem com ele.

Marin, Oliveira e Comar (2003) observam que a Educação Ambiental (EA) é complexa se analisada sob o campo teórico da percepção e do comportamento humano e afirmam que, para as mudanças em direção a práticas sustentáveis se refletirem no comportamento da sociedade, é necessário que se provoque a conscientização dos laços que existem entre ser humano e meio ambiente.

A EA deve ser política, fundamentada nos recursos humanos de uma organização, e deve atingir o pessoal da alta administração até a base da pirâmide organizacional, constituída pelos empregados mais simples (Dias, 2011).

Esse programa deve passar pelas mãos de um ator, um educador. Sorrentino et al. (2014) destacam a figura do Educador Ambiental Popular e salientam que uma série de características são necessárias para a formação do Educador Ambiental Popular. Não se trata, portanto, simplesmente de vontade, há todo um diálogo crítico e acolhedor.

Sorrentino et al. (2014) ainda explicam que o traçado de processos educacionais é pautado pela construção de arenas, espaços de aprendizagem, de diálogo, onde o que se quer ensinar tem como pré-requisito o desejo de aprender e o estímulo à capacidade de análise crítica do outro.

Sorrentino e Nascimento (2011) destacam também, nesse sentido, importantes aspectos sobre a questão da EA e sustentabilidade no âmbito universitário, que devem ser aplicados e aprofundados durante um processo de formação socioambiental.

O papel da universidade no campo da sustentabilidade e da EA precisa ser 
conhecido e aplicado nas instituições e constitui elemento fundamental para que o conceito seja replicado pelas gerações vindouras. A questão deve ser explorada e refletida entre docentes, discentes e servidores (Sorrentino \& Nascimento, 2011).

Percebe-se, assim, que a figura do educador ambiental é essencial no processo de implantação de práticas sustentáveis nas organizações, principalmente tendo como ambiente uma universidade que possui uma importante relação com o ensino, com a educação.

\section{MÉTODO DE PESQUISA}

Como estratégia de pesquisa, o estudo de caso foi escolhido por investigar um fenômeno contemporâneo dentro do seu contexto da vida real, especialmente quando os limites entre o fenômeno e o contexto não estão claramente definidos (Yin, 2003).

O estudo foi conduzido tendo como referência o método qualitativo, que tem o ambiente natural como fonte direta dos dados e o pesquisador como instrumento-chave: os estudos qualitativos têm como preocupação básica o mundo empírico em seu ambiente natural (Yin, 2003).

Estudos de Bakhtin (1975) citados por Fiorin (2008) relatam que a linguagem, em seu caráter distintivo, possui uma propriedade dialógica, pois perpassa pela palavra do outro, que é dotada de enunciados próprios e também do discurso alheio. A língua é desintegrada em enunciados compostos por dialogismo (Fiorin, 2008).

O enunciado produzido, na visão de Bakhtin (1975), permite expor e remeter a questões não presentes diretamente no discurso, como, por exemplo, lembranças de outros enunciados remetidos àquele assunto (Fiorin, 2008).

As expressões dialógicas podem se apresentar com certa adversidade ou contradição, aceitação ou recusa, divergência ou convergência e, nesse sentido, os enunciados são espaços para vozes sociais e sujeitam-se a contestação. Nessas vozes, situam-se as relações dialógicas sociais e individuais identificadas pela teoria bakhtiniana (Bakhtin, 2010).

Com essa fundamentação, foram estudadas as ações voluntárias realizadas em uma universidade brasileira que operacionalizou, através de seus próprios servidores, projetos ambientais para diversos setores e áreas de atuação.

A universidade pública em questão, por meio de sua superintendência, propôs aos seus servidores técnicos, como agentes administrativos espalhados em diversos campi, o desafio de criar um projeto sustentável que envolvesse a própria área ou setor em práticas sustentáveis.

Num primeiro momento, a proposta compôs um grupo de pessoas que apre- 
sentavam perfil de inovação e de liderança, que aqui são denominados os gestores dos projetos. Esses gestores, separados por áreas, trabalharam em grupos afins durante aproximadamente um ano, com a tarefa de apresentar uma proposta sustentável para algumas pessoas e, ao mesmo tempo, fazer com que esse grupo atingido fomentasse a experiência a outras pessoas da organização.

Importante destacar que, nesse processo, os gestores foram submetidos a um programa de formação que trabalhou conceitos e posturas a serem adotadas e desempenhadas. A adesão ao programa teve caráter voluntário.

O esquema de formação apresentava o conceito de arquitetura da capilaridade, que pretendia alcançar os servidores numa rede horizontal de multiplicadores, que foram denominados "Pessoas que Aprendem Participando" (PAPs), conforme ilustrado na Figura 2.

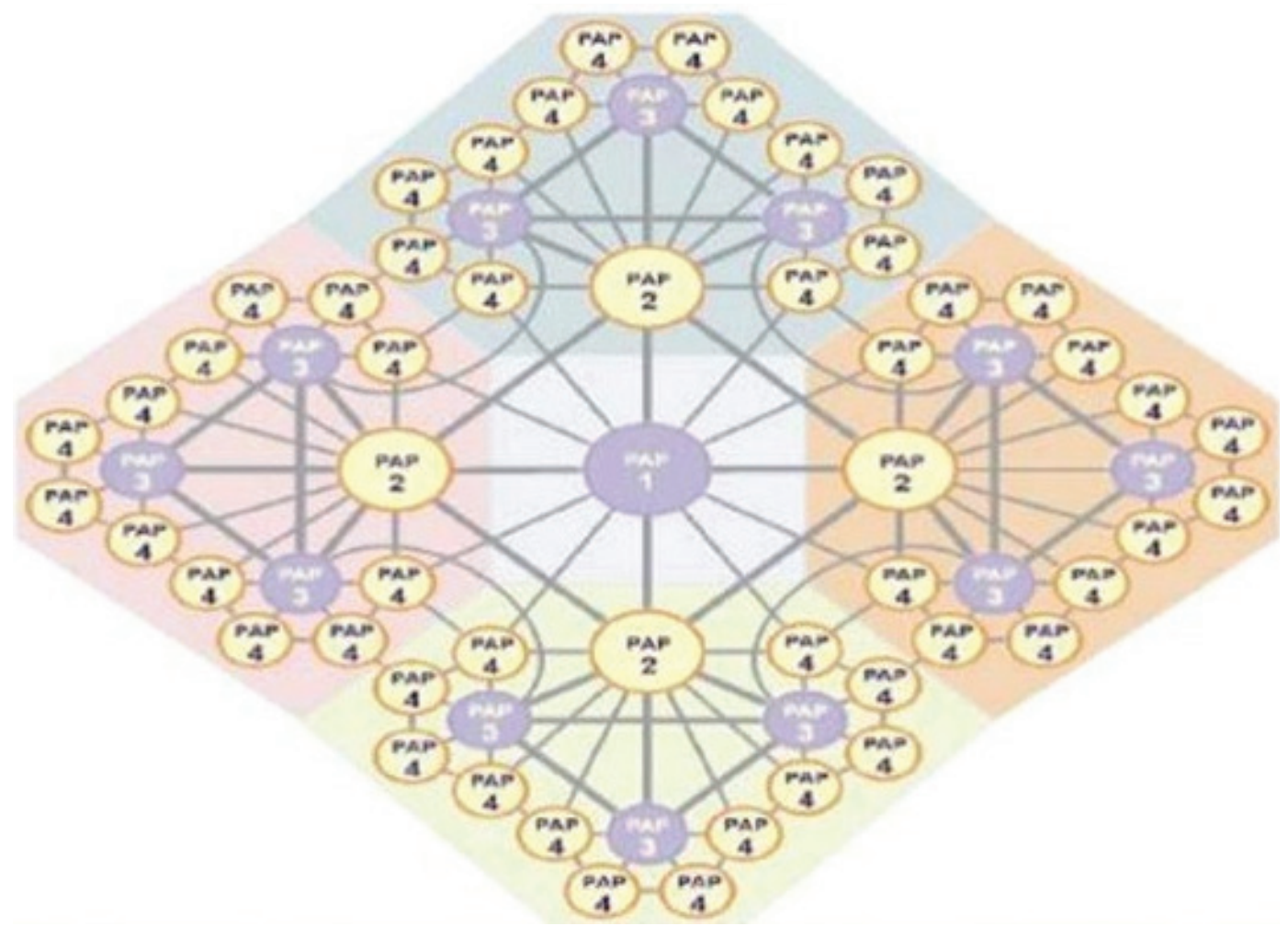

Figura 2 - Arquitetura da capilaridade na formação Fonte: Silva (2006).

O sistema de formação em capilaridade PAPs remete a dois significados 
articulados e complementares - "pesquisa-ação-participante" e "pessoas que aprendem participando" -, constituindo-se como uma comunidade aprendente, interpretativa e afetiva, de vida e de sentido, num lugar para bons e humanizadores encontros e para a práxis (Ferraro Júnior \& Sorrentino, 2005).

Um dos projetos implantados por esses servidores voluntários em um dos campi buscou ações práticas sustentáveis na gestão dos processos públicos, direcionadas para o uso racional do papel e a implantação da gestão eletrônica.

O projeto para redução de papel consistia em pequenas ações para reduzir a quantidade de papel gerada no setor público, como, por exemplo, impressão frente e verso, promoção da digitalização de processos entre secretarias (evitando cópias de processos), uso paralelo de um software para auxiliar na comunicação de chefias e pares no envio de documentos (ofícios e memorandos).

Este trabalho busca uma análise processada com base na coleta de opinião dos gestores do projeto (PAP2), de todos participantes envolvidos com as práticas (PAP3 e PAP4) e de parte significativa dos não envolvidos.

A coleta de dados ocorreu com a aplicação de questionários. Esse método é importante por apresentar, segundo Ruiz (1997), elementos otimizadores, como economia de tempo, eliminação de deslocamentos e obtenção de grande número de dados.

Os temas discutidos nos questionários foram os conhecimentos sobre o assunto, os motivos da participação ou não, os desafios para implantação de práticas sustentáveis e a opinião dos entrevistados sobre o processo.

Os questionários foram encaminhados por e-mail, e os respondentes foram esclarecidos de que suas identidades estavam resguardadas e que as respostas serviriam de base para a elaboração de um trabalho de cunho acadêmico e científico. Todo o trabalho procedeu de forma voluntária.

Os entrevistados foram separados nos seguintes grupos: grupo 1 - pessoas que não participaram do projeto de práticas sustentáveis; grupo 2 - gestores responsáveis pela implantação do projeto; e grupo 3 - pessoas que participaram do projeto das práticas sustentáveis.

No grupo 1, constituído de 15 servidores, nove pessoas aceitaram a participação na pesquisa. Já no grupo 2, constituído de três servidores, todos aceitaram a participação na pesquisa. Por sua vez, o grupo 3 foi constituído de cinco pessoas, sendo que quatro servidores aceitaram a participação na pesquisa.

Os questionários foram encaminhados na semana seguinte à conclusão dos trabalhos institucionais elaborados para implantação de práticas sustentáveis na gestão pública da universidade estudada.

Para o grupo 1, aplicaram-se as seguintes perguntas: 1 - Você se considera uma 
pessoa consciente das necessidades atuais relativas ao meio ambiente? 2 - Quais os motivos para sua não participação no projeto de Gestão Uso do Papel × Gestão Eletrônica ocorrido no campus? 3 - Sobre a metodologia da capilaridade aplicada no projeto em questão, o que você achou? 4 - Na sua realidade de trabalho, você considera possível o uso racional do papel e a implantação da gestão eletrônica no setor público?

Para os grupos 2 e 3, aplicaram-se as seguintes perguntas: 1 - Quais motivos te levaram a participar desse processo de formação aplicado no campus? 2 - Realize um autoavaliação sobre sua participação e relação com o processo. Considere, por exemplo: sua dedicação, interesse, condições objetivas. 3 - Sobre a metodologia da capilaridade indique: a) aspectos positivos/negativos, vantagens e contribuições. 4 - O que considera como fatos negativos e positivos do processo? 5 - Você considera possível o uso racional do papel e a implantação da gestão eletrônica no setor público. Por quê?

\section{APRESENTAÇÃO E DISCUSSÃO DOS RESULTADOS}

$\mathrm{Na}$ análise das respostas do grupo 1, composto por aqueles que não participaram do projeto de práticas sustentáveis, foi realizado um comparativo das respostas e percebeu-se um reconhecimento da importância ambiental, porém os entrevistados demostraram pouco domínio sobre o assunto. Muitos declararam não realizar atitudes conscientes sobre esse tema e reafirmaram a impossibilidade de mudanças em seus hábitos para atingir a finalidade proposta.

Ao serem questionados sobre os motivos da não adesão às ações sustentáveis propostas, os entrevistados ressaltaram os seguintes motivos: indisponibilidade de tempo, falta de apoio das chefias e incompreensão do método aplicado pelo projeto de implantação de práticas sustentáveis no campus.

Ao se perguntar a esse grupo se o uso racional do papel e a implantação da gestão eletrônica no setor público seriam possíveis, as respostas enfatizaram que há uma forte necessidade de conscientização, regulamentação específica e altos investimentos em software/hardware.

$\mathrm{Na}$ análise dos dados que compreendem o grupo 2, formado pelos gestores responsáveis pela implantação do projeto, os entrevistados afirmaram que o principal motivo para propor práticas sustentáveis - gestão de papel × gestão eletrônica - foi a insatisfação do excesso de papel gerado pelo serviço público e, com isso, a falta de espaço para arquivo de um lado e, de outro, a facilidade em transferi-los para arquivos digitais.

Na questão a respeito do interesse pessoal dos gestores ao longo da implan- 
tação do projeto, foi possível perceber desânimo na aplicação dos trabalhos, já que os gestores declararam haver muita resistência dos servidores não participantes.

Quando se perguntou a esse grupo o que seria necessário para o uso racional do papel e a implantação da gestão eletrônica no setor público, o grupo ressaltou que é necessário um envolvimento institucional na aplicação de um programa obrigatório. Os gestores entrevistados indicaram o fato de a adesão e a participação serem voluntárias como uma questão complicada.

Os entrevistados do grupo 2, ao serem perguntados sobre sua avaliação final das atividades realizadas, mencionaram que avaliam o processo como positivo, pois obtiveram aprendizado simples que diminuiu um pouco o uso do papel, ou seja, as práticas foram adotadas.

$\mathrm{Na}$ análise do grupo 3 , por sua vez, as pessoas que participaram do projeto das práticas sustentáveis demonstraram que a maior dificuldade para o uso racional de papel e a implantação de gestão eletrônica foi o desconhecimento quanto à legislação específica, pois a gestão de documentos no setor público implica processos burocráticos que muitas vezes são repetitivos por exigência da lei.

O grupo 3 também identificou a falta de padronização dos serviços públicos como um problema recorrente, pois a mesma unidade de uma instituição adota modelos diferentes para o mesmo processo.

A respeito da implantação e da dificuldade para realização das práticas, percebe-se que os grupos tiveram percepções diferentes sobre o assunto principal, conforme detalhado na Tabela 2.

Tabela 2 - Principais dificuldades na execução das ações propostas

\begin{tabular}{c|l}
\hline Grupo & \multicolumn{1}{c}{ Principais dificuldades } \\
\hline Não participaram & $\begin{array}{l}\text { Indisponibilidade de tempo; } \\
\text { Falta de apoio das chefias; } \\
\text { Incompreensão do método aplicado pelo projeto. }\end{array}$ \\
\hline Gestores & $\begin{array}{l}\text { Resistência dos servidores; } \\
\text { Falta de envolvimento das chefias. }\end{array}$ \\
\hline Participaram & $\begin{array}{l}\text { Desconhecimento quanto à legislação específica; } \\
\text { Falta de padronização dos serviços públicos. }\end{array}$ \\
\hline
\end{tabular}

Fonte: elaborada pelos autores (2016).

\section{CONSIDERAÇÕES FINAIS}


Quando se trata de implantar práticas sustentáveis em instituições, é necessária uma comunicação efetiva, que seja construída numa sólida e participativa educação ambiental e que se enquadre no modelo organizacional de administração pública.

Mesmo pequenos procedimentos implantados necessitam de incentivos, base legal e reconhecimento dos superiores para que as ações sejam constantes e os servidores estejam confortáveis na execução.

A legislação brasileira, conforme mencionado neste artigo, avançou muito em questões ambientais, principalmente no que tange às normas que instituem licitações e contratos da administração pública, porém ainda é necessário avançar sobre documentação digital na aplicação de arquivos públicos.

Nota-se que a cultura dos serviços públicos tende a ser um contraponto no desenvolvimento de um sistema de gestão eletrônica, pois o servidor está acostumado, por exemplo, a ter a cópia dos documentos circulantes pelo setor como forma de comprovação de fatos ocorridos e como sua própria garantia do dever cumprido.

As práticas sustentáveis no setor público, como propostas por Vogelmann (2014), não apresentam dificuldades na realização da tarefa em si, mas o que torna difícil a implantação dessas práticas é o comportamento habitual do ser humano para realizar a atividade, a cultura da resistência a mudanças.

Por isso, os funcionários da instituição devem estar envolvidos e conscientes das questões ambientais. Nesse contexto, destaca-se a figura do educador ambiental, que se coloca como agente preparado para a implantação de práticas em uma atmosfera incipiente.

No estudo de caso apresentado, foi possível identificar as dificuldades existentes e perceber que elas são próprias de uma organização pública. Esse espaço necessita de maior enquadramento legal e mais envolvimento organizacional para a implantação de práticas sustentáveis.

Nesse sentido, por serem escassas, é necessário um registro sobre a implantação de práticas sustentáveis em setores públicos, como também a publicação de casos de sucesso que apontem para um sistema completamente sustentável na gestão pública.

Uma solução para a questão apresentada é a existência de uma fundamentação legal estruturada que ampare o servidor público em suas ações e o assegure no manuseio de informação e no seu envolvimento em cursos e atividades sobre consciência sustentável.

As questões dialógicas apresentadas e subtraídas das entrevistas denotam 
que um trabalho de educação continuada sobre o assunto tende a favorecer a inclusão de práticas sustentáveis no dia a dia do servidor de forma natural.

A ruptura com o sistema tradicional, de forma brusca e desvinculada de uma cadeia organizacional que envolva a toda a instituição, favorece a resistência dos servidores, por isso é importante a revisão de todo o modelo a que o sistema se condiciona.

\section{REFERÊNCIAS}

Bakhtin, M. (2010). Marxismo e filosofia da linguagem. São Paulo: Hucitec.

Bergue, S. T. (2010). Comportamento organizacional. Florianópolis: Departamento de Ciências da Administração da UFSC.

Brasil (2016). Lei n 9.795, de 27 de abril de 1999. Dispõe sobre a educação ambiental, institui a Política Nacional de Educação Ambiental e dá outras providências. Diário Oficial da União, Seção 1, Brasília, DF. Recuperado de http://www.planalto.gov.br/ccivil_03/leis/19795.htm

Brasil (1993). Lei no 8.666, de 21 de junho de 1993. Regulamenta o art. 37, inciso XXI, da Constituição Federal, institui normas para licitações e contratos da Administração Pública e dá outras providências. Diário Oficial da União, Seção 1, Brasília, DF. Recuperado de http:// www.planalto.gov.br/ccivil_03/ leis//8666cons.htm

Costa, L. G., Damasceno, M. V. N., \& Santos, R. de S. (2012). A Conferência de Estocolmo e o pensamento ambientalista: como tudo começou. Âmbito Jurídico, XV(105). Recuperado de http://www.ambito-juridico.com.br/ site/?n_link=revista_artigos_leitura\&artigo_id=12292

Couto, H. L. G. do, \& Coelho, C. (2015). Fatores críticos no comportamento do gestor público responsável por compras sustentáveis: diferenças entre consumo individual e organizacional. Revista de Administração Pública, 49(2), 519-543.

Da Conferência das Nações Unidas para o Meio Ambiente Humano, em Estocolmo, à Rio-92: agenda ambiental para os países e elaboração de documentos por Comissão Mundial sobre Meio Ambiente e Desenvolvimento. (2012). Em discussão!, (1), Senado Federal, Brasília, DF. Recuperado de http://www.senado.gov.br/noticias/Jornal/emdiscussao/rio20/a-rio20/conferencia-das-nacoes-unidas-para-o-meio-ambiente-humano-estocolmo-rio92-agenda-ambiental-paises-elaboracao-documentos-comissao-mundialsobre-meio-ambiente-e-desenvolvimento.aspx

Dias, R. (2011). Gestão ambiental: responsabilidade social e sustentabilidade. 
São Paulo: Atlas, 232 p.

e-ARQ Brasil: Modelo de Requisitos para Sistemas Informatizados de Gestão Arquivística de Documentos (2011). Câmara Técnica de Documentos Eletrônicos. 1.1. versão. Rio de Janeiro: Arquivo Nacional. Recuperado de http://www.siga. arquivonacional.gov.br/images/publicacoes/e-arq.pdf Faraco, C. A. (2009). Linguagem \& diálogo: As ideias linguísticas do Círculo de Bakhtin. São Paulo: Parábola Editorial.

Ferraro Júnior, L. A., \& Sorrentino, M. (2005). Formação Socioambiental de Servidores da USP. Recuperado de http://www.educacaoambiental.sga.usp. $\mathrm{br} /$ ?page_id $=2538$

Fiorin, J. L. (2008). Introdução ao pensamento de Bakhtin. São Paulo: Ática.

Hernandes, J. M. da C., \& Caldas, M. P. (2011). Resistência à mudança: uma revisão crítica. Revista de Administração de Empresas, 41(2), 31-45.

Lakatos, E. M., \& Marconi, M. A. (2003). Fundamentos de metodologia científica. São Paulo: Atlas.

Marin, A. A., Oliveira, H. T., \& Comar, V. (2003). A Educação Ambiental num contexto de complexidade do campo teórico da percepção. Interciencia: Revista de Ciencia y Tecnologia da América, 28(10).

Ranieri, V. E. L., \& Delliti, W. B. C. (2014). Ambientalização nas instituições de educação superior no Brasil: Caminhos trilhados, desafios e possibilidades. São Carlos, SP: EESC/USP.

Rua, M. das G. (2012). Políticas públicas. Florianópolis: Departamento de Ciências da Administração da UFSC.

Ruiz, J. A. (1997). Metodologia científica: Guia para eficiência nos estudos. São Paulo: Atlas.

Silva, M. (2006). ProFEA: Programa Nacional de Formação de Educadores Ambientais. Documento técnico MMA DEA. Recuperado de http://www.mma. gov.br/estruturas/educamb/_arquivos/dt_08.pdf

Santos, M. C. D., \& Cruz, M. C. S. (2017). Governo eletrônico e transparência: desdobramentos sobre publicidade e controle externo das contas públicas municipais. UNINGÁ, 52(1), 137-143.

Sorrentino, M. et al. (2014). Encontros e caminhos: Formação de educadoras(es) ambientais e coletivos educadores, 3. Brasília: MMA/DEA.

Sorrentino, M., \& Nascimento, E. (2011). Universidade e Políticas Públicas de Educação Ambiental. Educação em Foco, 14(2), 15-38.

Sorrentino, M., Trajber, R., Mendonça, P., \& Ferraro Júnior, L. A. (2005). Educação 
AS DIFICULDADES NA IMPLANTACÃO DE PRÁTICAS SUSTENTÁVEIS NA GESTÃO PÚBLICA: ESTUDO DE CASO DE UNIVERSIDADE PÚBLICA BRASILEIRA - USO RACIONAL DE PAPEL VERSUS GESTÃO ELETRÔNICA

ambiental como política pública. Educação e Pesquisa, 31(2), 285-299.

Vogelmann. J. C. Jr. (2014). Roteiro prático de ações sustentáveis na administração pública. Porto Alegre: ESAF.

Yin, R. K. (2003). Estudo de caso: Planejamento e métodos. Porto Alegre: Editoração Eletrônica; Artmed.

Zanella, L. C. H. (2012). Metodologia de estudo e de pesquisa em Administração. Florianópolis: Departamento de Ciências da Administração da UFSC. 